\section{The many faces of interaction}

\author{
P. A. Reynolds, ${ }^{1}$ R. Mason ${ }^{2}$ and J. Harper ${ }^{3}$
}

VERIFIABLE CPD PAPER
IN BRIEF

- Explores how people in general, and teachers and students in particular, interact with ICT when learning.

- Describes the ICT-human interfaces that currently occur in education.

- Describes the use of mobile technology and portable digital assistants in a clinic to help in decision making and administration.

- The interactive opportunities for developing e-portfolios using social software are highlighted.

During the process of learning teachers and/or students interact with each other on a personal level. However, in e-learning the process is achieved through the intermediary of an information and communication technology (ICT) system or service. Descriptions of these ICT-human interface devices are given in this paper. Successful interaction depends not just on personal relationships, but also on understanding and the ability to use computers and communications equipment effectively. Interactivity, when using ICT, may as a result be different from that in a traditional classroom. The computer is the main man-machine interface and modulates people's ability to interact. Newer, mobile technology will extend the ability to interact in terms of time and place, as is illustrated by the use of portable digital assistants for dental teaching in clinics. The paper concludes that it is very important that both teachers and students should understand how to interact optimally with current and future ICT systems and devices.

\section{E-LEARNING IN DENTISTRY}

Section A: Teaching and technology

1. A description of the new technologies used in transforming dental education

2. Seeing is believing: dental education benefits from developments in videoconferencing

3. Webcasting: casting the web more widely

4. Top of the pops - CD-ROM and DVDs in dental education

Section B: Informatics: better informed by systems and services

5. Better informed: an overview of health informatics

6. Better informed in clinical practice a brief overview of dental informatics

7. Digital clinical records and practice administration in primary dental care

Section C: Impact of e-learning in

dental education

8. Remember the days in the old school yard: from lectures to online learning

9. An intricate web- designing and authoring a web-based course

10. The many faces of interaction

11. Supporting the learner and teacher online

12. Making a mark - taking assessment to technology

13. Continuing professional development and ICT: target practice

14. Assuring quality

Section D: A connected future

15. Nine years of DentEd: a global perspective

16. A vision of dental education in the third millenium

\section{INTRODUCTION}

Previous papers in this series have suggested that, in a successful e-learning scenario, interactivity is a vital ingredient. There is always an important relationship between all those involved in the teaching and learning process, even if that relationship is mediated by a machine. In many respects it is the bedrock of education, for as Mason ${ }^{1}$ observes - 'Interaction between learners and teachers has continuously been shown to provide cognitive benefits, as well as to assist in the effective and motivational aspects of learning.' ${ }^{1}$

However, it cannot be assumed that interactivity is purely concerned with personal relationships. In e-learning most of the relationships will be

\footnotetext{
${ }^{1 *}$ Professor of Dental Education, Centre for Flexible Learning in Dentistry, King's College Dental Institute, Floor 3, Strand Bridge House, 138-142 Strand, London, WC2 $1 \mathrm{HH}^{2}{ }^{2}$ Professor of Educational Technology, Institute of Educational Technology, The Open University, Walton Hall, Milton Keynes, MK7 6AA; ${ }^{3}$ T Manager, The Dental Institute at Guy's, King's and St Thomas' NHS Hospitals, King's College Hospital, Denmark Hill, London, SE5 9RW

${ }^{*}$ Correspondence to: Professor P. A. Reynolds Email:P.A.Reynolds@kcl.ac.uk
}

\section{Refereed Paper}

DOI: 10.1038/sj.bdj.2008.409

${ }^{\oplus}$ British Dental Journal 2008; 204: 565-570 mediated through ICT systems and services, in a situation that depends on the often-criticised man-machine interface.

Interactivity obviously exists in a traditional classroom setting and it is face-to-face and personal. Teachers teach and ask questions, students learn, give answers and interact amongst themselves. Some would see this as the strength of the traditional pedagogical methodology and its apparent lack as a weakness of its e-learning counterpart. However, writing about online university degree programmes at a university in the United States, Cannings and Tolley $(2000)^{2}$ state: 'online encourages a degree of community of practice and the level of reflection well beyond that found in students who participate in graduate school by attending weekly face-to-face classes'. ${ }^{2}$ Their reason for this claim is the ongoing value of education which they characterise as "the continuation of the dialogue in between any official synchronous online classes or occasional face-to-face meetings... a sort of 24/7 (twenty-four hours a day, seven days a week) type of presence that has not existed in education before. ${ }^{2}$

Four types of communications have been delineated. ${ }^{3}$ They are: 
- Teacher-to-student group

- Teacher-to-individual student

- Student-to-teacher

- Student-to-student.

The author also states that it is customary... to distinguish between "public" modes of interaction such as bulletin boards, emails or "open" chat environments; and "private" one-to-one exchanges such as individually addressed email messages'. The author then claims that the traditional classroom favours the teacher-student group model in which the limited opportunities for communications between teacher and an individual student are compromised by a 'lack of privacy and confidentiality'.

Student-to-student communication is also limited by constraints of 'time and place at which this type of interaction can take place.' There are both differences and similarities between the interaction inherent in face-to-face situations when compared with those mediated through ICT systems. It has been pointed out that: "Even people we "know" in other circumstances may not interact with us in the same way within computer-mediated contexts. It is possible to change your identity online, and even your gender.' ${ }^{3}$ Furthermore, electronic learning spaces often encompass a greater range of participants than is customary within traditional classrooms. ${ }^{4}$

Further comments describe the way we represent ourselves in the physical world as including 'aspects of our appearance, our voices, our facial expressions, our clothes and other possessions, our chosen companions, and so on. ${ }^{4}$ On the other hand, "where the self is revealed solely through electronic mediated text this richness of information is obviously not available. ${ }^{4}$ This observation does not take account of visual ICT media such as videoconferencing, where these personal traits and accoutrements can be seen and experienced, albeit at a distance.

Experience with videoconferencing suggests that any initial reservations about such a teaching method are quickly dispelled. In a report on the use of video in the delivery of continuing professional development for dentists, it was observed that 'students in the larger lecture group did... feel camera shy at first, but as the presenter moved amongst the audience with a microphone, the discussion improved. ${ }^{5}$ It was also noted that 'The students were obviously interested and concentrated well. An attention span of more than 16 minutes was timed which compares well with the face-toface lecture span of 9 minutes. ${ }^{5}$

Some will argue that web-based distance learning causes persistent frustrations that inhibit educational opportunities, ${ }^{6}$ such as:

- Too many emails, not all of which are read

- Difficulties interacting with technology and the web

- Lack of feedback and help from tutors.

This is a situation that has to be addressed by both teachers and learners through course design, training and support, all subjects which will be covered in future papers in this series.

\section{TALKING TO TECHNOLOGY}

Although there may be a debate about the nature of relationships within elearning, there is no doubt that both teachers and students have to interact with technology. The use of pen and paper - perhaps the historic technologies - may well appear simple, but are they, in reality, any different from the use of a computer? We might be more at ease reading a book rather than reading off a screen, but this may well be a cultural and generational factor, ie older people may be likely to be happier in a paperbased world than younger generations who have grown up with ICT.

For both teachers and students the ICT system that they most frequently interact with is the computer, although the use of internet-connected mobile devices is becoming pervasive. It may seem less natural and more complicated than putting pen to paper; as they have to have confidence in their abilities to use the intermediaries - the keyboard, screen and mouse. The importance of these man-machine interfaces is demonstrated in the words: 'At a more practical level, even factors such as the lack of expertise at keyboarding can have a marked effect on choice of words and structure of sentences, giving an "impression" of the writer which might be significantly at odds with that obtained during a faceto-face conversation. ${ }^{4}$

There is still debate as to whether or not the QWERTY keyboard is the best method of inputting text into a computer. Since 1874, this has formed the normal model for no better reason than it was the optimum arrangement to reduce typebar clashes on the first - manual - typewriters. Now it is the "universal user interface.'

The only other mode of inputting that has been tried is voice recognition. This has to some extent been the 'holy grail' of the ICT industry; much has been promised, but delivery has been difficult with the user having to 'train' the system, often talking like a robot to ensure accuracy of recognition. However, a voice response system in a call centre can be satisfactorily responsive to simple words like 'yes' and 'no' and numbers.

Voice or speech recognition is the ability of a machine or program to receive and interpret dictation, or to understand and carry out spoken commands. The human voice's analogue signals have to be converted into digital signals; to decipher these a computer has to have a digital database, ie a vocabulary of words and syllables, and a fast method of comparing this data with the incoming signals. The size of this vocabulary depends upon the computer's RAM (random access memory) capacity and the best systems have all words, syllables etc stored in the RAM rather than having to search the hard disk for some of the matches.

Nevertheless, total accuracy cannot be guaranteed. Extraneous noises such as coughs and barking dogs can lead to false input and there are problems with similarly sounding words such as 'here' and 'hear'. Despite these drawbacks voice recognition has some applications, notably as a security device for authorising access to banking services, and to buildings. Other uses have mainly been for 'repetitive data entry operations. This includes dictation of medical notes and case histories in the health sector, for which there is a burgeoning market (our italics). ${ }^{8}$

Given that it enables hands-free operation of computers and other ICT systems and, in time, mobile equipment such as personal digital assistants and increas- 


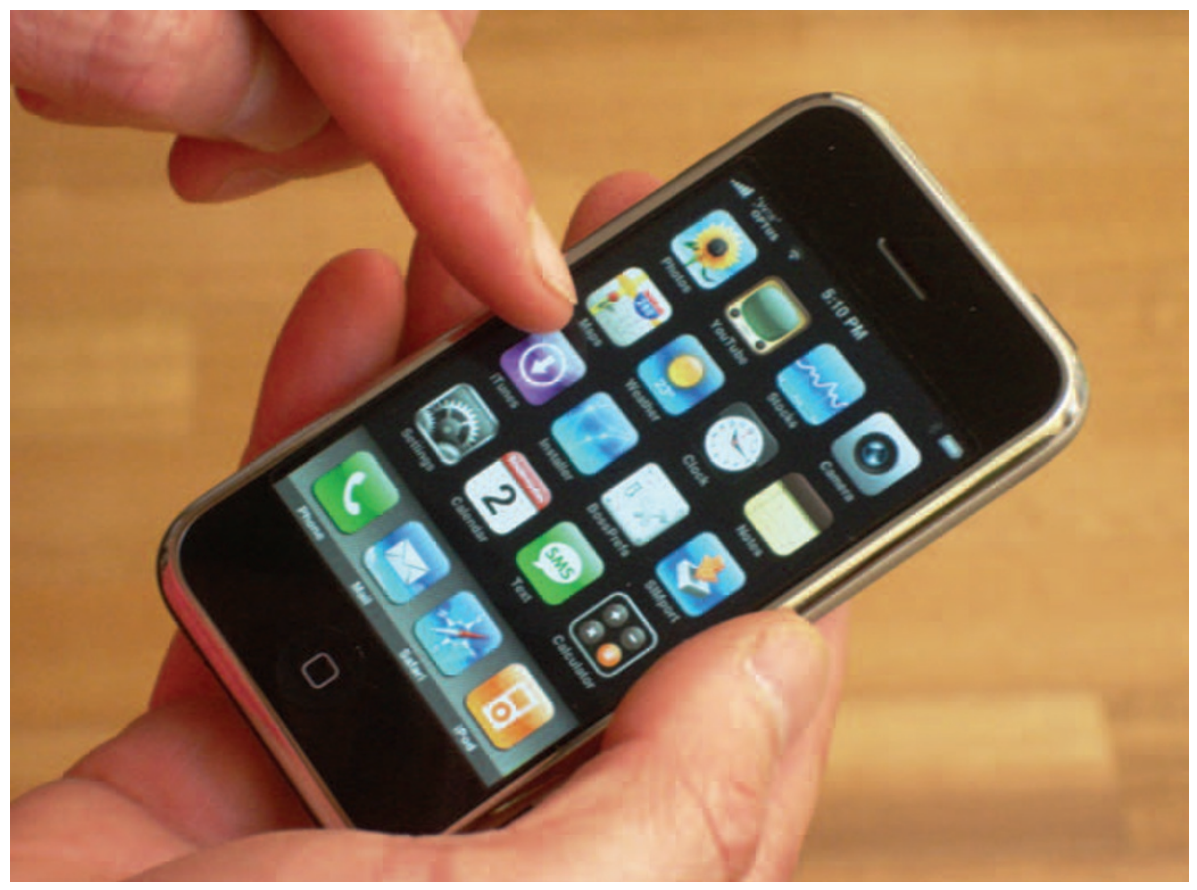

Fig. 1 Touch screen smart phone with the functionality of a PDA and mobile communications with internet connectivity

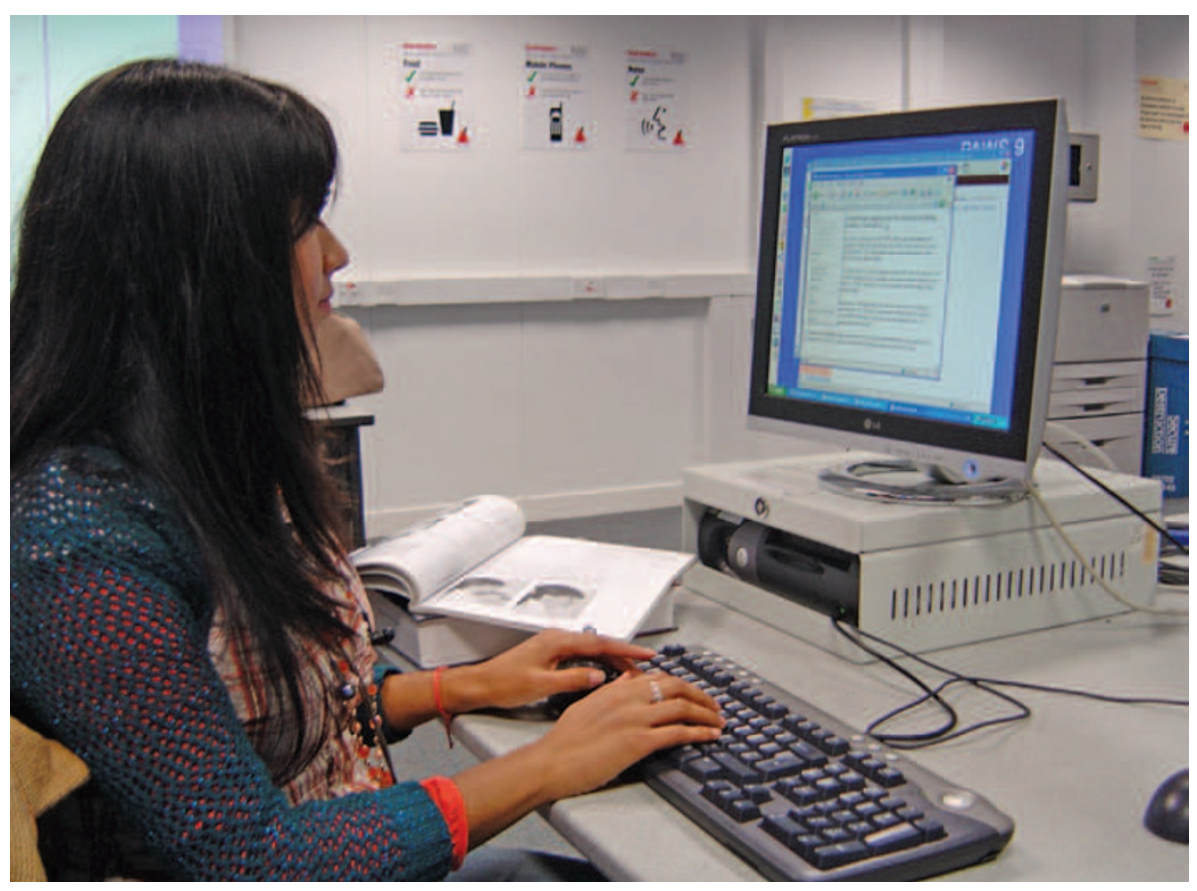

Fig. 2 Dental student interacting with flat screen monitor and keyboard in combination with more traditional media such as books

ingly smartphones (Fig. 1), chairside applications in both dental education and practice can be foreseen. Notwithstanding this, the question of whether voice recognition will replace the QWERTY keyboard as the main method of computer inputting remains open to doubt, particularly in the short and medium-term.

\section{OF MICE AND SCREENS}

The ubiquitous mouse, in conjunction with the graphical user interface (GUI),
- Controlling the computer

- Controlling the software programmes on the computer.

A typical PC mouse system has the following parts:

- Sensors (eg opto-mechanical movement detectors)

- A mouse controller which reads the state of sensors and records the current mouse position

- A communication link

- A data interface

- A driver

- Software.

When information changes, the mouse controller sends a packet of data to the computer data interface controller. The mouse driver in the computer receives the data packet and decodes the information and directs the application software or operating systems.

Recent mouse developments are offering different data transmission techniques to reduce desk top cable clutter. Wireless - also used for keyboards - laser and even optical versions are now available, as are Bluetooth ${ }^{\circledR}$ models which can operate over longer distances.*

e-Learners spend a considerable amount of time staring at a screen, with the potential danger of eye-strain. Fortunately, most modern screens have eliminated the annoying 'flicker' and with larger screen sizes and much improved text and pictorial display and background, user experience is much improved. In addition, monitor filters, such as privacy and antiglare filters, help to decrease computer screen glare and reduce viewing from the side.

Despite emanating from television, the more common computer display technology is the CRT (cathode ray tube), distinguished by its bulky importance. ${ }^{9}$ Newer techniques such as liquid crystal display have led to the development of flat screens, which are rapidly replacing the CRT versions (Fig. 2). They also take up less space on a desk.

${ }^{*}$ Bluetooth ${ }^{\circledR}$ is a short-range wireless specification that allows radio connection between devices including computers, printers, headsets and mobile phones as well as mice, within a 10-metre range of each other. Up to seven compatible devices can communicate simultaneously using Bluetooth. 
A number of standards have been introduced for the resolution offered by monitors. These started with VGA (video graphics array), since when various versions have been developed to improve the screen resolution. VGA had a resolution of $640 \times 480$ pixels* whereas the latest - UXGA (ultra-extended graphics array) offers up to $1,600 \times 1,200$ pixels.

The resolution of a screen is expressed as the number of pixels arrayed horizontally and vertically; thus, as stated above, the UXGA standard has a resolution of up to $1,600 \times 1,200$ depending on the number of colours displayed. Obviously the higher the resolution, the better the quality of the picture, but the perception of this naturally depends on the user's visual acuity with or without glasses.

Screen sizes are normally measured in inches diagonally from one corner to the other; the key factor in choosing a monitor is the viewable area, not necessarily the quoted screen size. It is also worth noting that the size of the viewable area affects the resolution. A low resolution on a larger screen will produce a fuzzy image, so large-size screens should have a higher resolution.

\section{APPEARANCE MATTERS}

It may not be generally known that it is possible to change the settings of the interfaces to suit personal preferences and situations. This is particularly useful for disabled people, although altering the touch and feel of the computer can improve the man-machine interface for all users. As one website observes: 'Every computer user is an individual... Yet the computer we may spend many hours on each day is set up to meet the needs of an amorphous average person.'

The website goes on to list typical changes that can be made to make the screen, keyboard and mouse more suitable for the user. ${ }^{9}$ Included in the list are:

1. Making the text easier to see on the screen by imposing a preferred text size on any website visited

2. Changing the screen background colour or reversing text out of a black background

${ }^{*}$ A pixel is the basic unit of programmable colour on a computer display.

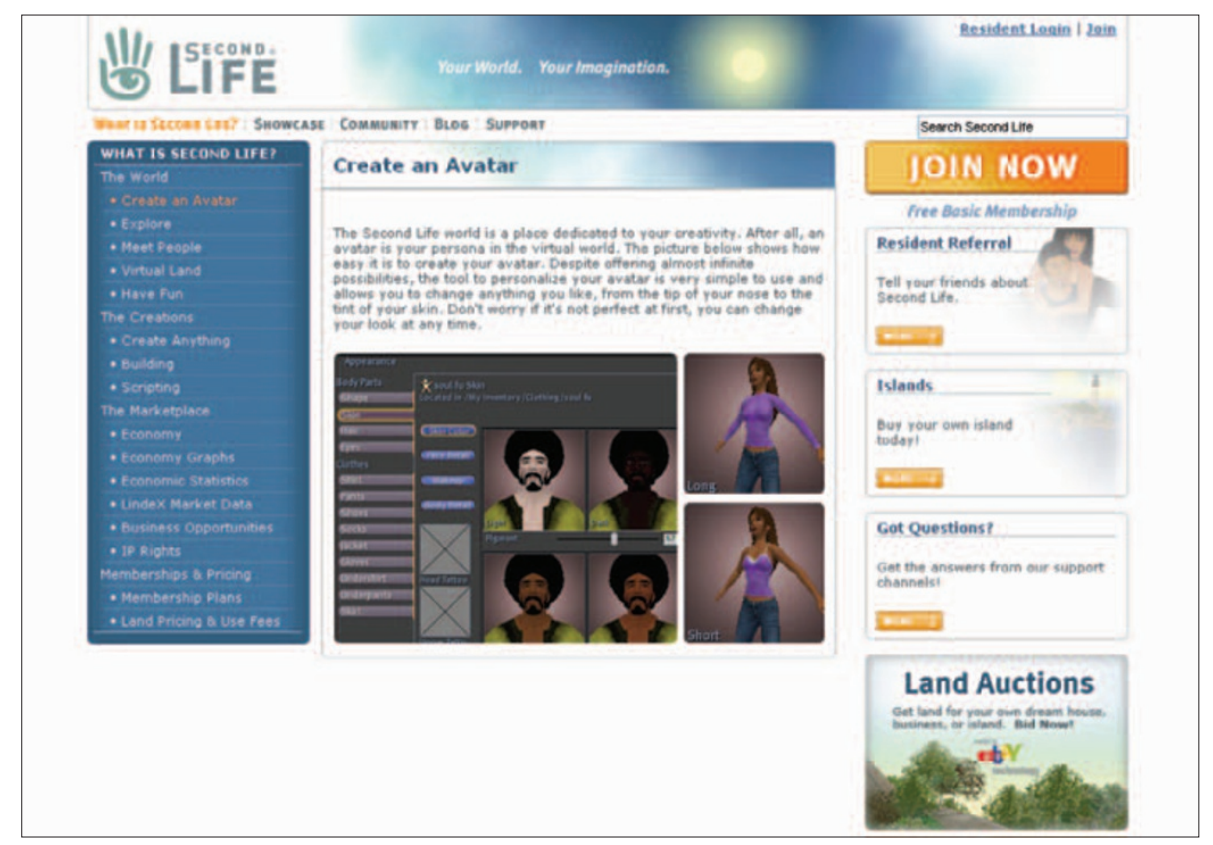

Fig. 3 Screenshot of Second Life avatar page

3. In Microsoft's Windows XP there is a feature that makes locating the mouse much easier. The standard mouse pointer, the website advises, ‘isn't very easy to see and many people find that they can't spot where it is located, or they lose it as they move it across the screen.'

\section{LOCATION, LOCATION, LOCATION}

The other question that e-learning poses is where does the interaction take place? By its very nature it is unlikely to take place on a single site where everybody is co-located. More likely it will take place as various forms in cyberspace - virtual classrooms, bulletin boards, chatrooms and videoconferencing sessions. These impersonal methods may appear to lack the interactive advantages of a faceto-face situation. However, one opinion based on personal experience is that this possible downside 'has been partly overcome by the availability of chatrooms, emails and bulletin boards. ${ }^{10}$ In fact, research has shown that 'shrinking violets, who in normal circumstances rarely open up, often blossom in the Internet gardens.' ${ }^{11}$

In support of this, one commentator makes the point that 'online discussion can potentially be more engaging, more inclusive and perhaps more democratic than in face-to-face situations. Shy, less verbally articulate, slight of voice or slower responders can spend time considering their responses before submitting them and have equal access when being displayed online. ${ }^{12}$

This is supported by an evaluation of online learning amongst undergraduates in which it was suggested that 'cyberspace provided an easier mode for expressing one's feelings about a learning experience generally, and about online learning in particular. ${ }^{13}$

\section{MOBILE INTERACTION}

We have placed our emphasis on the computer as the main method for interfacing. However, the penetration and application of mobile technology means that the location may not have a desk. Evidence of this comes from a trial at a UK dental school, the aim of which was to evaluate the use of PDAs amongst undergraduate students. In this trial the point of interaction was at the chairside. ${ }^{14}$

The dental school's academic network was linked to a secure encrypted wireless network which connected to the PDAs. This allowed students to access a virtual learning environment (VLE) and, through it, appropriate teaching resources and material. These included text-based documents featuring teaching notes, illustrative images and textural extracts, PowerPoint presentations, PDF documents, instructional images, simple animations such as clinical procedures or patient safety/emergency procedures, and viewable webcasts. The WebCT 
interface enabled students to send emails, post notes to a bulletin board and enter personal or clinical details.

As the PDA is a mobile device, all the interaction can take place at the chairside, allowing the students to receive guidance while undertaking clinical practice. This also has major implications with the introduction of electronic patient records (EPRs) for these too can be accessed, consulted and updated via the mobile device.

The PDA proved to be a highly acceptable mode of access to online education; their small size and mobility enabled students to use them in a variety of learning activities such as note-taking, downloading materials and receiving ICT-based information. Positive responses from students, even those with limited ICT experience, and the time saved in record-keeping and note-taking indicate that a PDA-based approach to mobile computing is highly applicable in healthcare environments.

A mobile solution is also being sought in the completion of e-portfolios on- and offline using the " $m$-portfolio"15 The interactive potential of e-portfolios - the new digital identity - is discussed below.

\section{A MORE CONNECTED FUTURE}

There is now an emerging literature on the socio-cognitive interactions and their assessment that will allow further evaluation of this new and clearly acceptable way of mobile interaction. ${ }^{16}$ The authors make no distinction between technology and people but explore the dynamic interaction between those who are advancing 'knowing'. This 'conversational' process has a snowball effect between those in the dialogue as they grow their understanding within their own context. ${ }^{17}$ With mobile learning there are new relationships between traditional and mobile learning in which global conversation has a central role. This is especially important as the new, more connected Web 2.0 facilitates such mobile communications. ${ }^{18}$ The emergence of more social software such as 'Facebook', 'YouTube' and 'Second Life' is providing new interactive domains. The latter (http://secondlife.com) creates 3D personalised worlds where the players choose embodiments of themselves (avatars) (Fig. 3). ${ }^{19}$ Emerging immersive worlds will inevitably offer ever-new opportunities for interacting with people and places where the only limitation is the bandwidth, the software and the user's own imagination.

Furthermore, the development of haptic devices (gloves or jigs) will enable even more senses to be involved in this interaction. Virtual reality is discussed later in this series, but one key issue is the disorientation that can occur when using these devices. Motion sickness can also occur as part of this disorientation and this is well documented in 3D viewing. ${ }^{20}$ However, whether it is pen and paper media or a human interface device of a computer mediating the interaction, once this interface becomes automatic or unconscious, the communication can occur freely. Assistive technology* will inevitably help those users with disabilities and the world will become an ever smaller place. ${ }^{21}$

\section{REWINDING THE STORY}

e-Portfolios are the latest, somewhat poorly-defined concept that has captured the imagination of educationalists. One general definition suggests that 'an e-portfolio is an electronic space for learners to store their work - to share with others and to show to teachers (and, sometimes) employers. ${ }^{22}$ Another, in the healthcare context states 'the ePortfolio is a purposeful collection of information and digital artefacts that demonstrates development or evidences learning outcomes, skills or competencies. ${ }^{23}$

The potential to create a portfolio offers an interactive process, that allows the learner to 'collect, select, reflect, connect and project and present'. ${ }^{24}$ Projection in this sense is the direction of the next steps to be taken and presentation of the e-portfolio can be submitted for assessment purposes.

Creating a personally-owned learning record through the use of multiple

${ }^{*}$ Assistive technology (AT) is a generic term that includes assistive, adaptive and rehabilitative devices and the process used in selecting, locating and using them. AT promotes greater independence for people with disabilities by enabling them to perform tasks that they were formerly unable to accomplish, or had great difficulty accomplishing, by providing enhancements to or changed methods of interacting with the technology needed to accomplish such tasks. ${ }^{21}$ media can now benefit from interactive social software such as blogging, wikis, podcasting and multimedia tools. 'Eportfolios help you to become the person you are to be. ${ }^{25}$ Even though there are challenges in interoperability between the many systems available, there is no doubt that interactive, student-focused log books will become essential in reassuring future employers and patients that the professional has a well thoughtout and proven track record.

\section{CONCLUSION}

For the successful use of ICT in dental education, it is essential that the importance of the factors influencing interactions between teachers, students and the different forms of ICT are understood and that the lessons that have been learned in this area are applied.

1. Mason R. Using communications media in open and flexible learning. London: Kogan Page, 1994.

2. Cannings T A, Tolley S G. Online university degree programmes. In Watson D M, Downes T (eds) Communciations and networking in the networked society. pp 149-156. Dordrecht, The Netherlands: Kluwer Academic Publishers, 2000.

3. Turkle S. Life of the screen: identity in the age of the Internet. London: Weidenfield and Nicolson, 1996.

4. Dowling C. Social learning within electronic environments. Current perspectives and future directions. In Nicholson P, Barrie Thompson J, Ruohonen M, Multisilta J (eds) e-Training practices for professional organizations. pp 205-212. Dordrecht, The Netherlands: Kluwer Academic Publishers, 2005.

5. Reynolds P A, Mason R D. Online videomedia for the continuing professional development in dentistry. Comput Educ 2002; 39: 65-98.

6. Hara N, Kling R. Students' frustrations with a web-based distance education course. First Monday 1999; 4(12). http://firstmonday.org/issues/issue4 12/hara/index.html (accessed 30 March 2008).

7. The QWERTY connection website. http://home. earthlink.net/ dcrehr (accessed 30 March 2008).

8. AbilityNet. My computer my way website. http://www.abilitynet.org.uk/myway (accessed 30 March 2008)

9. Howstuffworks website. http://www. howstuffworks.com (accessed 30 March 2008).

10. Reynolds PA. e-Learning gets results for Europe's largest dental school. Br J Healthc Comput Inf Manage 2005; 22: 30-32.

11. McDougall $A$, Clark T, Campbell $L$. Taking the e-train in university education. In Nicholson $\mathrm{P}$, Barrie Thompson J, Ruohonen M, Multisilta J (eds) e-Training practices for professional organizations. pp 85-92. Dordrecht, The Netherlands: Kluwer Academic Publishers, 2005.

12. Hellstén M. Anybody out there a real expert? In Nicholson P, Barrie Thompson J, Ruohonen M, Multisilta J (eds) e-Training practices for professional organizations. pp 51-60. Dordrecht, The Netherlands: Kluwer Academic Publishers, 2005

13. Dowling C. Social interactions and the construction of knowledge in computer-mediated environments. In Watson D M, Downes T (eds) Communciations and networking in the networked society. pp 165-174. Dordrecht, The Netherlands: Kluwer Academic Publishers, 2000.

14. Reynolds PA, Cox M J, Dunne S, Myint Y K, Harper J. Portable digital assistants (PDAs) in dentistry: Part II - pilot study of PDA use in the dental clinic. Br Dent J 2007; 202: 477-483. 
15. Cotterill S J, Angarita M, Horner P et al. Towards the m-portfolio. Proc ePortfolios 2006. Oxford, 2006. http://www.eportfolios.ac.uk/fdt/4 docs/47_mPortfolio_paper_for_ePortfolio_2006. doc (accessed 1 April 2008).

16. Sharples M, Taylor J, Vavoula G A. Theory of learning for the mobile age. In Andrews R, Haythornthwaite C (eds) The Sage handbook of e-learning research. Thousand Oaks, CA: Sage Publications Ltd, 2007.

17. Laurillard D. A conversational framework for individual learning applied to the 'learning organisation' and the 'learning society'. Syst Res Behav Sci Res 1999; 16: 113-122.
18. Science learning opportunities in Second Life. Dental Information and Library Innovation weblog, University of Michigan, 2007. http://mblog.lib. umich.edu/dentlib/archives/resources/education/ index.html (accessed 31 March 2008)

19. O'Reilly T. What is Web 2.0? Design patterns and business models for the next generation of software. http://www.oreillynet.com/pub/a/oreilly/ tim/news/2005/09/30/what-is-web-20.html (accessed 30 March 2008).

20. Smith S P, Marsh T. Evaluating design guidelines for reducing user disorientation in a desktop virtual environment. Virtual Reality 2004; 8: 55-62. 21. Wikipedia. Assistive technology. http://
en.wikipedia.org/wiki/Assistive technology (accessed 30 March 2008).

22. Mason R. Handbook of research on e-portfolios - Ali Jafari \& Catherine Kaufman. Br J Educ Technol 2007; 38: 174. (Review)

23. Cotterill S J. What is an e-portfolio? http://www. eportfolios.ac.uk/definition (accessed April 12008 )

24. Mason R, Pegler C, Weller M. ePortfolios: an assessment tool for online courses. Br J Educ Technol 2004; 35: 717-727.

25. Cotterill S J, White A, Currant B. Using Web 2.0 to support PDP. PDP-UK Newsletter 2007; 12: 7-8. http://www.recordingachievement.org/downloads/PDP\%20UK\%20Dec\%20lssue\%2012.pdf 